\title{
PWR effect on crack initiation under equi-biaxial loading development of the experiment
}

\author{
Cédric Gourdin ${ }^{1, *}$, Gregory Perez ${ }^{1}$, Hager Dhahri ${ }^{1}$, Stéphan Courtin $^{2}$, Jean Christophe Le Roux ${ }^{3}$, \\ and Habibou Maitournam ${ }^{4}$ \\ ${ }^{1}$ DEN-Service d'Etudes Mécaniques et Thermiques (semt), CEA, University of Paris-Saclay, 91191 Gif-sur-Yvette, France \\ 2 EDF, R\&D, Site de Saclay, 91290 Palaiseau Cedex, France \\ 3 EDF, R\&D, Site des Renardières, 77818 Moret sur Loing Cedex, France \\ ${ }^{4}$ IMSIA, UMR 9219, CNRS, CEA, EDF, University Of Paris-Saclay, 91762 Palaiseau, Cedex, France
}

Received: 9 January 2019 / Accepted: 25 September 2019

\begin{abstract}
The lifetime extension of the nuclear power stations is considered as an energy challenge worldwide. That is why, the risk analysis and the study of various effects of different factors that could potentially represent a hazard to a safe long term operation are necessary. The methodology for fatigue dimensions of the Pressurized Water Reactor components (PWR) is based on the use of design curves established from test carried out in air at $20^{\circ} \mathrm{C}$ on smooth specimens by integrating safety coefficient that covers the dispersion of tests associated with the effects of structures. To formally integrate these effects, some international codes have already proposed and suggested a modification of the austenitic stainless steels fatigue curve combined with a calculation of an environmental penalty factor, namely Fen, which has to be multiplied by the usual fatigue usage factor. The aim of this paper is to present a new device "FABIME2E" developed in the CEA-LISN in collaboration with EDF and AREVA. These new tests allow quantifying accurately the effect of PWR environment on semi-structure specimen. This new device combines the structural effect like equi-biaxiality and mean strain and the environmental penalty effect with the use of PWR environment during the fatigue tests.
\end{abstract}

Keywords: Multiaxial fatigue / PWR environment effect / austenitic stainless steel

\section{Introduction and aim}

The question of assessing the margins and safety factors in the fatigue analyses which are widely used today (ASME BPV III, RCC-M, JSME, EN-13445-3, etc... [1-4]) is a very challenging one.

The fatigue rules used today in the nuclear industry were initially built and integrated into the ASME code in the 1960s. Establishing fatigue rules is a challenge in itself since fatigue degradation depends on the wear of components which undergo repeated cycling: fatigue tests can therefore be very long and costly, if led on full-size components. As a result, the testing is in practice conducted on small laboratory specimens, which then triggers the question of how to extrapolate results to a full size component. Another difficulty is that the rules need to remain easy to apply in order to be applied for industrial engineering calculations. Since 2007, the USA with the NUREG/CR-6909 [1], have now included the evaluation of

\footnotetext{
* e-mail: cedric.gourdin@cea.fr
}

environmental effects in their official regulation. Indeed, on the curves presented in Figures 1 and 2, PWR water environment effect on the fatigue lifetime of material used in the manufacture of reactor components compared with the ANL fatigue life models which represent mean values of fatigue life in Air are illustrated.

The 304L and the 316L stainless steel are used for the manufacturing of the pressurized water reactors (PWR). Many components of this type of reactors are subjected to a multiaxial thermo-mechanical cycling $[5,6]$. Therefore, the multiaxial fatigue assisted by environment is considered as one of the main degradation mechanisms affecting the life of the PWR components.

To formally integrate these effects, some international codes have already proposed and suggested a modification of the austenitic stainless steels fatigue curve combined with a calculation of an environmental penalty factor, namely Fen, which has to be multiplied by the usual fatigue usage factor.

Unfortunately, there is no sufficient experimental data available concerning fatigue strength for the austenitic stainless steels subjected to structural loadings [7-11], 


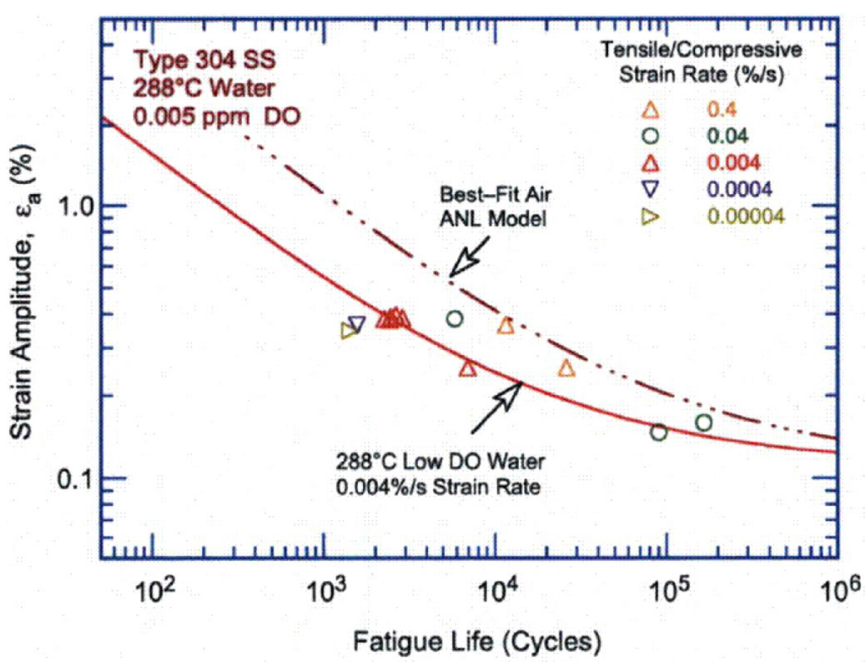

Fig. 1. Fatigue life of $304 \mathrm{~L}$ steel in PWR water compared with the ANL model Air curve [1].

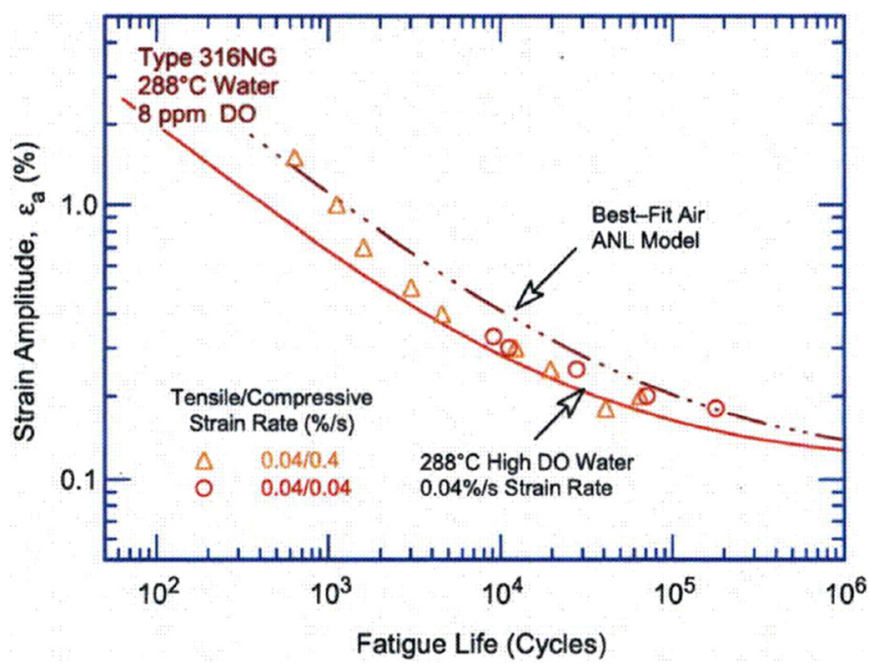

Fig. 2. Fatigue life of $316 \mathrm{~L}$ steel in PWR water compared with the ANL model Air curve [1].

which are used for power plants components. In order to obtain fatigue strength data under structural loading, biaxial test means with and without PWR environment were developed at LISN [12-14].

Two kinds of fatigue device have been developed. Within the same specimen geometry, structural loads can be applied in varying only the PWR environment.

The first device (FABIME2) is devoted to study the effect of biaxiality and mean strain/stress on the fatigue life. A second and new device based on FABIME2 is for the study of the impact of the environmental effect. With these new experimental results, we will highlight a PWR effect on the fatigue life of stainless austenitic steels.

\section{The first experimental device [14]}

To obtain an equi-biaxial strain state, we have chosen to apply different oil pressure values on each side of a

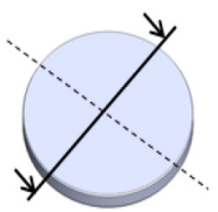

Pressure diaphragm

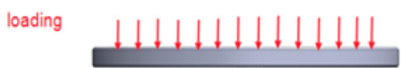

unloading

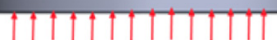

Fig. 3. Principle of the first fatigue test.

spherical diaphragm. The basic idea of the disc bending fatigue test was presented by Ives et al. [15] and Shewchuk et al. [16] about $50 \mathrm{yr}$ ago. In this test technique, a disc specimen is subjected to bending load by applying air pressure on the specimen surface. By altering the constraining condition at the edge of the specimen, a crack can be initiated at the specimen center even when a uniform thickness specimen is used, but the specimen diameter has been more than $250 \mathrm{~mm}$ [17]. In our case, to reduce the specimen diameter, the thickness is varying along the radius to initiate a fatigue crack at a specimen center and the possibility to increase the thickness has been kept. The objective of this first fatigue test was to dissociate the effect of the mean stress and equi-biaxial state loading. Indeed, we try to obtain a negative load ratio in order to get the same results as the uniaxial data and eliminate the residual strain.

In this study, equi-biaxial state loading generated from fatigue has been considered. It was used to optimize the geometry of a disk specimen refined in its center. It was used as a circumferentially embedded diaphragm with an applied pressure on both sides in order to obtain an equivalent strain in each loading direction in the plane (Fig. 3).

The experimental device called "FABIME2" is divided into four parts:

- fatigue cell which contains the spherical bending specimen,

- pressure generating system until 100 bars,

- electrical enclosure,

- homemade software developed under LABVIEW that provides control and acquisition data during the tests.

Two half-shells allow the positioning of the spherical bending specimen. Seal and embedment are realized by bolting these two parts.

Maximum experimental conditions are 100 bars for the pressure and $90^{\circ} \mathrm{C}$ for the temperature. An alternative differential pressure between the two sides of the spherical specimen is applied during the fatigue test. 


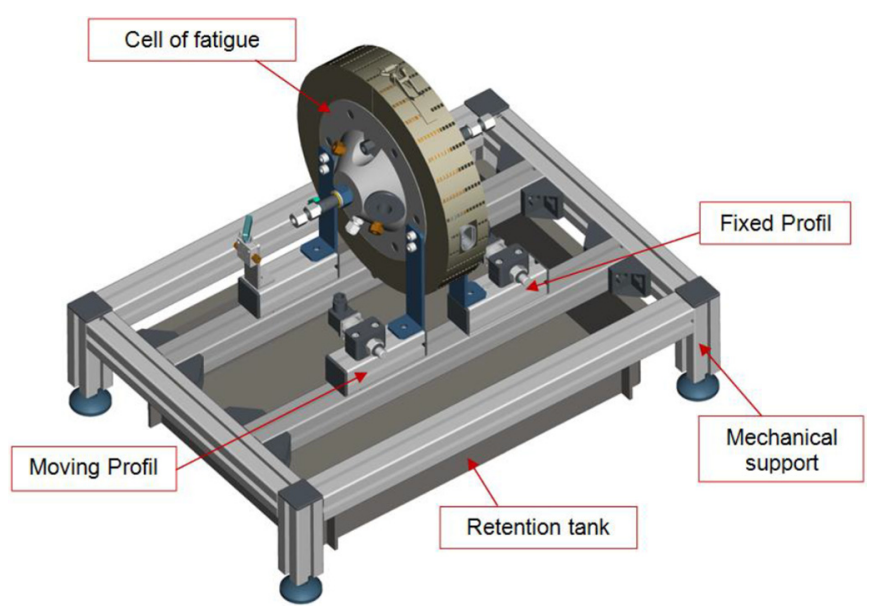

Fig. 4. View of the spherical bending device: fatigue cell.

To ensure well-defined experimental conditions, various measuring means are located symmetrically at the two half-shells:

- Pressure sensor with a measuring range between 0 and 100 bars.

- Type K thermocouple to measure the temperature of the fluid inside the fatigue cell.

- Displacement sensor (LVDT) to measure the deflection at the center of the spherical bending specimen. This sensor has a $5 \mathrm{~mm}$ range. Realizations of surface observations after the fatigue test show that the contact between LVDT and specimen is negligible (no fretting). No crack initiation is also observed directly under the LVDT.

- Two visualization windows on each half-shell, oriented at $45^{\circ}$ with a diameter of $20 \mathrm{~mm}$. The constitutive material is borosilicate glass with a permissible operating pressure of 100 bars.

The fatigue cell was built under European Security directives (Machines 2006/42/CE, Pression 97/23/CE) (Fig. 4).

\section{The experimental results [15]}

Biaxial fatigue tests were carried out on two austenitic stainless steels: "316L THY", and "304L CLI". The first material has been provided by Thyssen Krupp Materials France as a $15 \mathrm{~mm}$ thickness rolled sheet. The second material supplied by EDF is characterized by a thickness of $30 \mathrm{~mm}$ rolled sheet. In order to obtain a homogeneous austenitic phase, the sheet was subjected to a thermal treatment: keeping at high temperature (between 1050 and $1150{ }^{\circ} \mathrm{C}$ ) followed by rapid cooling.

\subsection{Fatigue tests on $316 \mathrm{~L}$}

The first fatigue test campaign was performed on austenitic stainless steel type 316L. Five levels of deflection were studied: $1.6 / 1.4 / 1.2 / 1.1$ and $0.9 \mathrm{~mm}$.

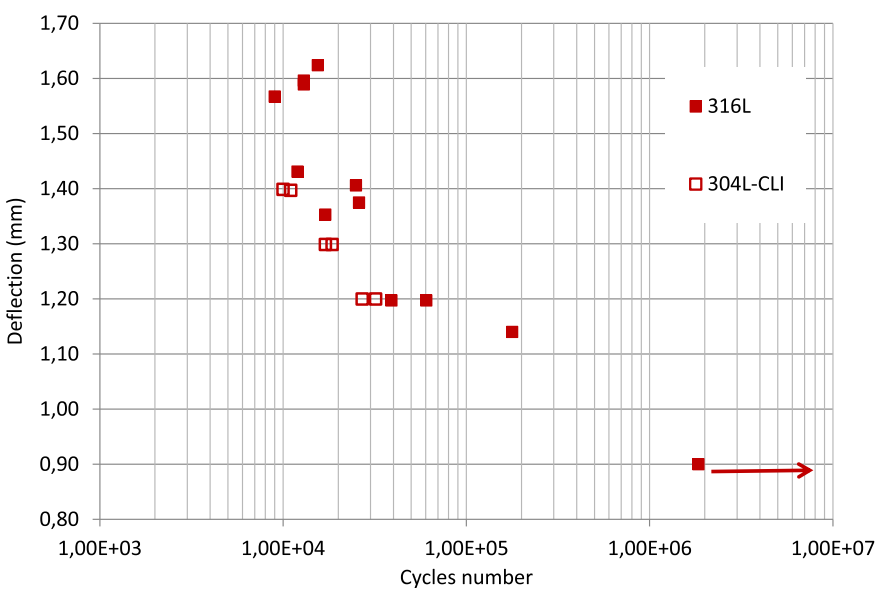

Fig. 5. Fatigue data obtained on the two austenitic stainless steels (316L and 304-CLI).

\subsection{Fatigue tests on $304-\mathrm{CLI}$}

In the frame of CEA-EDF-AREVA working group, a second fatigue test campaign was performed on austenitic stainless steel 304-CLI provided by EDF. This material completely agrees with the RCC-M and RCC-MRx [4] specification. Three levels of deflection were carried out $1.4 / 1.3$ and $1.2 \mathrm{~mm}$.

A first comparison of the experimental fatigue data between the two austenitic stainless steels (316L and 304CLI) is presented in Figure 5.

These experimental fatigue data show that $316 \mathrm{~L}$ steel undergoes longer fatigue lives than 304-CLI. However, the behavior of these two materials is slightly different, as 304CLI presents a secondary hardening unlike $316 \mathrm{~L}$.

\subsection{SEM observations of fracture surfaces}

SEM observations are realized on the surface crack of FABIME2 specimen, which has undergone an equi-biaxial fatigue loading of $1.4 \mathrm{~mm}$ in displacement are presented in Figure 6.

Two directions of crack propagation were observed: - In depth: striae of fatigue parallel to the specimen surface (Fig. 6a,b). The fatigue striae located at the junction between the two main cracks.

- On the surface: striae of fatigue perpendicular to the surface of the specimen (Fig. 6c).

At a higher magnification, we can distinguish crack propagation rivers. This demonstrates that the main crack propagates in the same time both in length and depth.

\section{Interpretation of the experimental results}

All tests performed in this study are carried out with imposed displacement (strain) with alternating load (without mean stress or strain), means with a stress ratio $R=-1$.

To compare the experimental data obtained from uniaxial and equi-biaxial tests, it is necessary to define a total equivalent strain. 

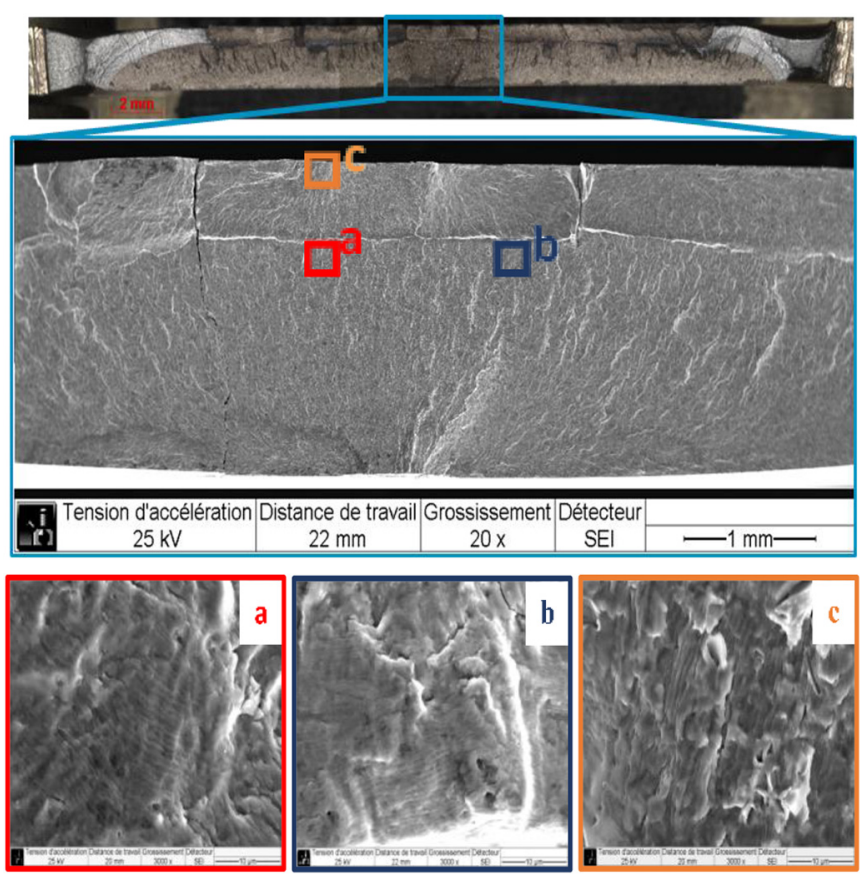

Fig. 6. Macroscopic observation of fracture surface.

Two definitions of equivalent strain are proposed: the first is based on the definition of von Mises (used in the RCC-MRx) and the second on the definition of TRESCA (used in the RCC-M, RSE-M).

Thus, the first equivalent strain used is the von Mises equivalent strain defined by the following equation:

$$
\Delta \varepsilon_{e q}=\sqrt{\frac{1}{1+v^{\prime}}(\Delta \dot{\varepsilon}: \Delta \dot{\varepsilon})}=\frac{2}{3} \frac{\left(1+v^{\prime}\right)}{\left(1-v^{\prime}\right)} \Delta \varepsilon_{1}
$$

with: $\Delta \dot{\varepsilon}$ : strain deviatoric component $\Delta \dot{\varepsilon}=\Delta \varepsilon-\frac{1}{3} \operatorname{tr}(\Delta \varepsilon)$, $\varepsilon_{1}$ the principal strain and $v^{\prime}$ the "real" Poisson's ration (elastic $v=0.3$ and plastic $v=0.5$ part) [2].

The second equivalent strain is the TRESCA equivalent strain defined by the following equation:

$$
\Delta \varepsilon_{e q}=\frac{1}{1+v^{\prime}} \operatorname{Max}\left|\varepsilon_{i}-\varepsilon_{j}\right| .
$$

The proposal approach to determine the level of the equivalent strain for each FABIME2 test is as follows:

- Determination of the value of the radial strain corresponding to the imposed deflection from the straindeflection calibration curve obtained in Figure 7a. With a similar mechanical behavior, the calibration curve can be used for the two materials.

- Determination of the von Mises or TRESCA equivalent strain from the relation between the radial strain and the equivalent strain (von Mises or TRESCA). This relation has been determined by elasto-plastic calculation of the fatigue test (Fig. 7b). These elastic-plastic behavior computations are used to determine the "real" value of
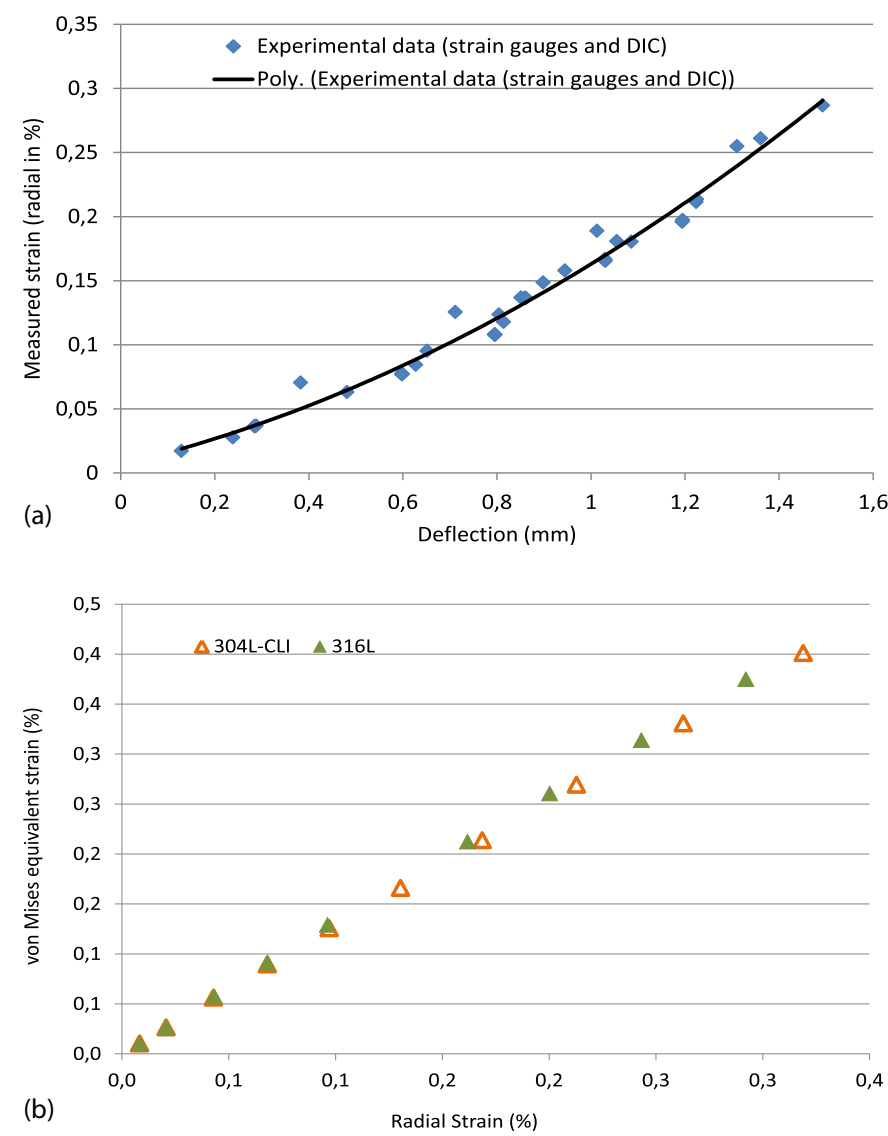

Fig. 7. Method to determine the equivalent strain versus the deflection. (a) Calibration curve: deflection versus radial strain. (b) Determination of the equivalent strain with the "transfer" curve: radial strain versus equivalent strain.

the Poisson's ratio by taking into account the elastic and plastic part. In our case, the Poisson's ratio is 0.415 for the largest deflection test $( \pm 1.63 \mathrm{~mm})$ and 0.396 for the lower deflection test $( \pm 0.9 \mathrm{~mm})$.

This method has been applied to the equi-biaxial fatigue tests presented earlier. The corresponding fatigue life curves are compared to that under uniaxial loading in Figure 8. Strain range is defined by the relation: $\Delta \varepsilon_{e q}=2 * \varepsilon_{\max }$. It appears that there is also no impact of equi-biaxial fatigue for the two types of materials, considering both von Mises and TRESCA equivalent strains [16].

\section{Specification of the new device FABIME2E}

The second fatigue device (FABIME2E, E for environment) has been developed to apply on the same specimen geometry the same structural loads in varying only the PWR environment.

Compared to FABIME2, specification changes for FABIME2E device mainly focused on the following points: - specimen is in contact with a PWR environment,

- an operating temperature of $340^{\circ} \mathrm{C}$,

- a maximum pressure up to $350 \mathrm{bar}$, 


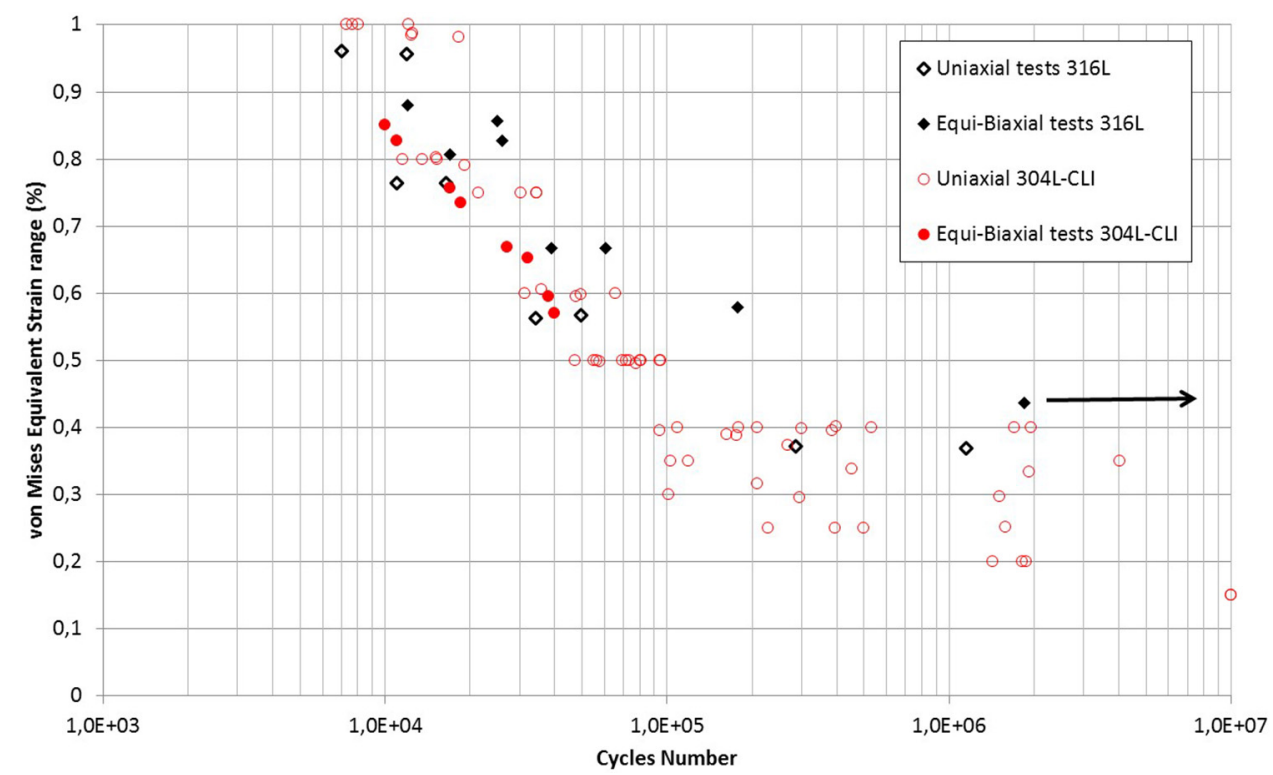

Fig. 8. Fatigue data obtained on the two austenitic stainless steels (316L and 304L-CLI).

- monitoring and adjustment of dissolved hydrogen level during testing,

- a perfectly flat and reproductive clamping of the specimen.

With these severe experimental conditions, four major technical difficulties had to be taken into account:

- the cohabitation of the PWR environment with the hydraulic oil at room temperature and 100 bar maximum;

- the PWR environment temperature stability: variations less than $1^{\circ} \mathrm{C}$ up to several weeks should be allowed in order to detect the initiation of cracks;

- monitor and adjust if necessary dissolved hydrogen level;

- the perfect sealing of the device during the tests.

A double cylinder system has been proposed to separate PWR and hydraulic fluids to apply a mechanical solicitation to the specimen (Fig. 9). A double acting cylinder would be moved by the hydraulic unit. Its movement would be mechanically transmitted (by the water incompressibility) to a primary cylinder to modify the volume of the PWR environment contained in each half-shell. Similar to FABIME2, this system applies a differential pressure, up to 100 bars, to the specimen. The difference here is that the pressure variation around the specimen is between 150 and 350 bar, respectively, the biphasic threshold of the PWR environment and the maximum pressure allowed by FABIME2E.

If the required pressure in the PWR environment is obtained by its constraint thermal dilation, this phenomenon must be avoided during the test. A variation of $1^{\circ} \mathrm{C}$ would cause a variation of several bars around the specimen. These pressure fluctuations may compromise the detection of the initiation of cracks by compliance. A stronger fluctuation could even lead the PWR environment

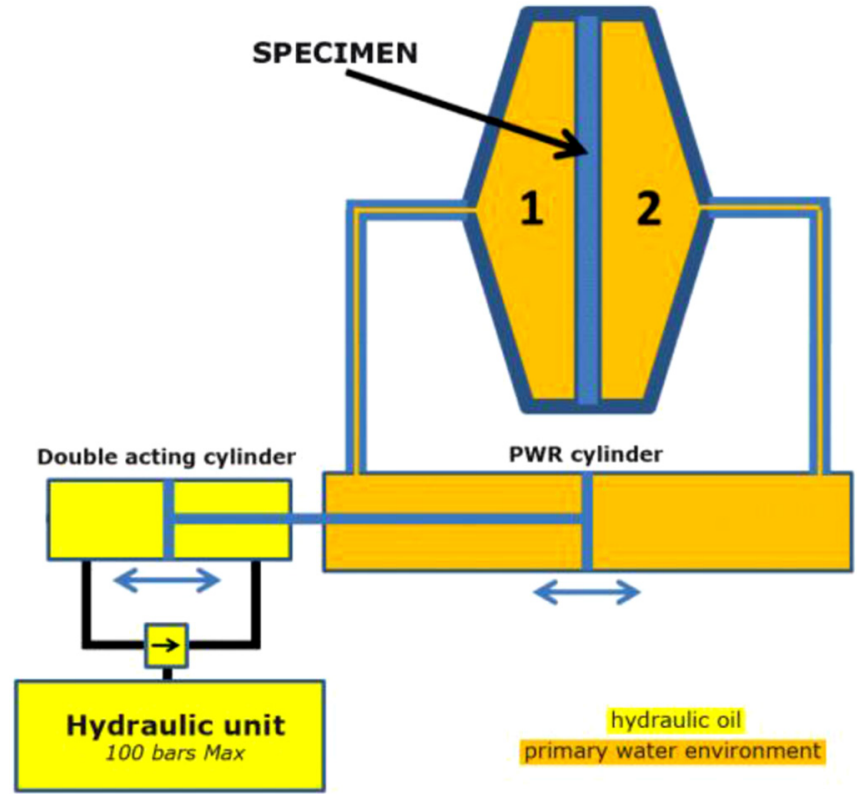

Fig. 9. Double cylinder system for separation of PWR and hydraulic fluid.

under its biphasic threshold. This would require a test stop. To avoid this, a temperature regulation system with a great stability was required.

The evolution of the chemical composition of the environment was one of the concerns for this new bench. Hydrogen is the most volatile part of this, so the ability to measure and if necessary adjust its level was needed.

In the end, the requested instrumentation would enable the monitoring of the evolution of the following data, for each half-shell: temperature, pressure, displacement and dissolved hydrogen level. 


\section{The new experimental device: FABIME2E}

The realization of FABIME2E was entrusted to French company TOP INDUSTRY. The maximum experimental conditions of the new device are 350 bar and $340^{\circ} \mathrm{C}$.

The main organs of this new device are:

- a cell consisting of two half shells for holding the specimen,

- a hydraulic clamping system is achieved by four hydraulic bolt tensioners to ensure flatness, sealing and repeatability,

- a sealing system compatible with the PWR environment,

- a closed PWR environment circuit,

- a "double cylinder" system to apply the mechanical solicitations on the specimen,

- an accurate and reliable heating system,

- a system for measuring and adjusting the level of dissolved hydrogen in the PWR environment,

- instrumentation for temperature, pressure, displacement (Fig. 10).

Because of much higher pressures and temperatures, the FABIME2E cell has more imposing dimensions than its predecessor FABIME2 (Fig. 11). However, the specimen geometry remains absolutely identical to be usable indifferently on the both test benches. For mechanical and hydraulic reasons (two kinds of environment, oil and PWR), the maximum frequency of loading is limited at $1 \mathrm{~Hz}$.

\subsection{Instrumentation}

Each half- shell has the following instrumentation:

- two type $\mathrm{K}$ thermocouples, positioned at the top and bottom with an uncertainty of calibration measured at $0.2^{\circ} \mathrm{C}$;

- a pressure sensor with a $0-400$ bar range with a linearity of $0.06 \%$ of FS and an uncertainty of calibration at 0.4 bar;

- a LVDT compatible with the PWR environment, with a displacement range $\pm 5 \mathrm{~mm}$ to measure the deflection of the specimen, with an uncertainty of calibration measured at $6.3 \mu \mathrm{m}$;

- two hydrogen sensors Pd - Ag from AREVA: one for measuring and one for adjusting the dissolved hydrogen level if necessary.

\subsection{Clamping and sealing}

Two metal rings are disposed on each side of the specimen to ensure the sealing of the cell during the test period. Clamping is achieved by means of a hydraulic clamp machine to ensure flatness, sealing and repeatability. Height heavy section attachment studs ensure the two half shells clamping around the specimen (Fig. 10).

\subsection{PWR environment}

FABIME2E cell has a $100 \mathrm{ml}$ volume. After filling the cell and high-pressure pipes the heating achieves the desired

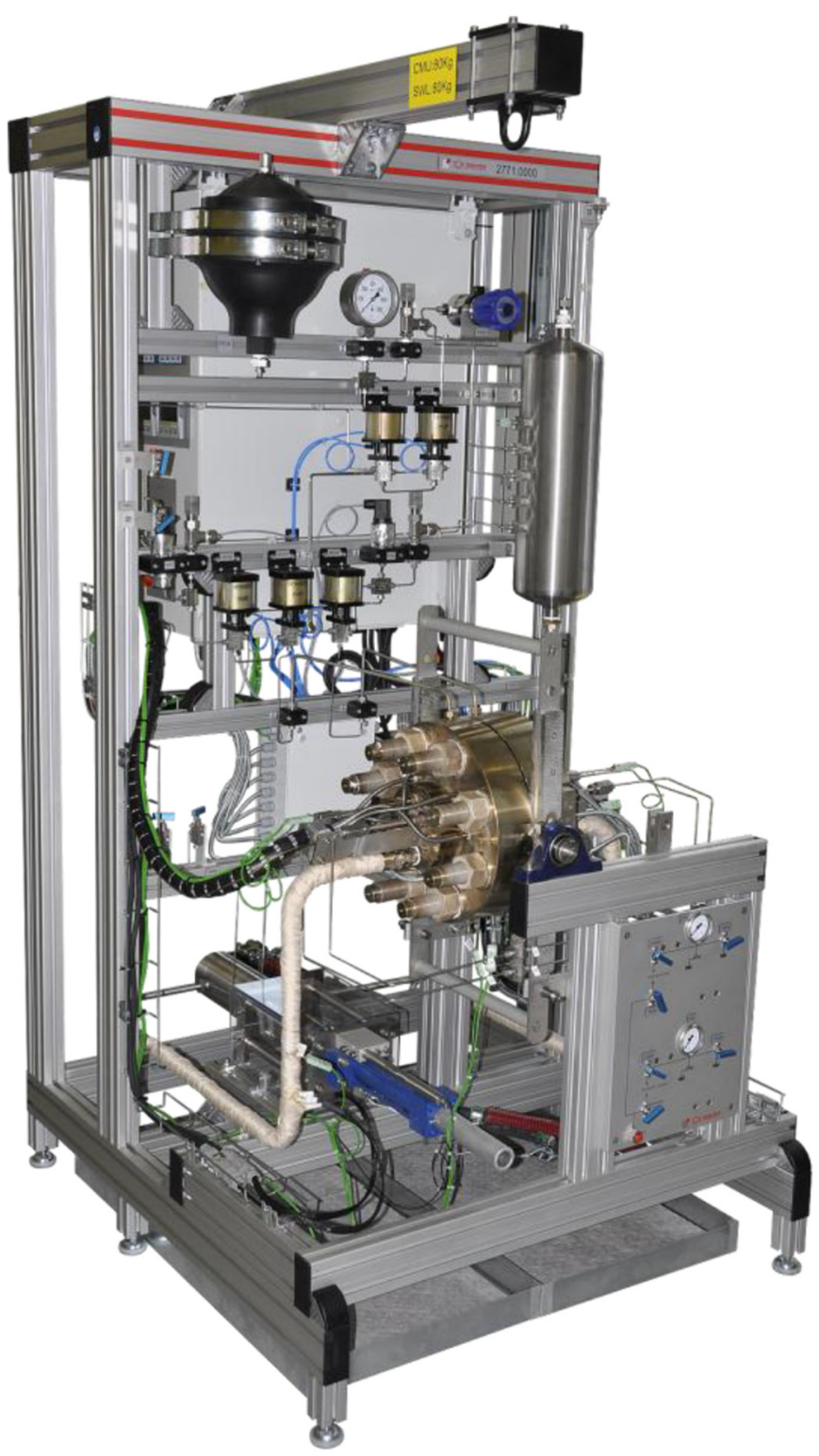

Fig. 10. View of the fatigue new bending device FABIME2E.

pressure because of the thwarted thermal dilation of the primary water (Fig. 12).

The integration of four $\mathrm{Pd}-\mathrm{Ag}$ sensors makes the dissolved hydrogen level measurement and modification possible.

\subsection{Heating}

Eight cartridge heaters with an output of $250 \mathrm{~W}$ each are located on each half-shell to reach the nominal temperature of $340^{\circ} \mathrm{C}$. The temperature rise is carried out at a maximum rate of $1^{\circ} \mathrm{C} / \mathrm{min}$. The maximum allowable temperature is $400^{\circ} \mathrm{C}$. Although the primary cylinder is at room temperature, a part of the pipes which connects it to each half-shell is also temperature controlled. Two EUROTHERM controllers (NANODAC model) ensure the regulation of the 4 heating zones. 


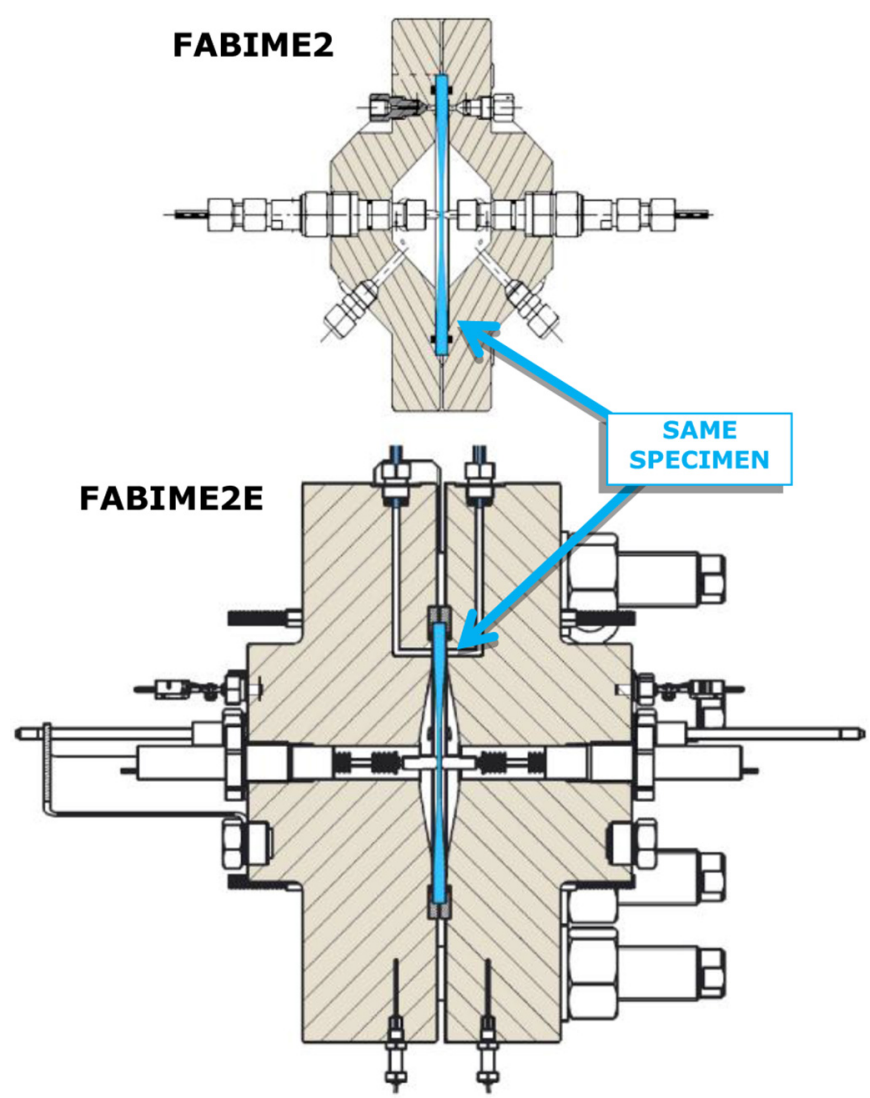

Fig. 11. Comparison between FABIME2 and FABIME2E fatigue cells (same scale and specimen geometry).

\subsection{Mechanical solicitation}

The same hydraulic group provides oil to both FABIME2 and FABIME2E test benches.

As shown in Figure 9, a hydraulic cylinder allows transmitting loadings to the primary cylinder to deform the specimen.

As it is possible to do with the bench FABIME2, pressure, displacement or strain control is allowed. The development of the control software in the CEA laboratory allows great flexibility: cycling shape, holds, control mode modifications, mean pressure or strain.

\subsection{Tests control}

The low-level tasks such as security management, hydraulic control and data reading require determinism and speed of processing. That is the reasons why they are devolved to real-time autonomous software running on a COMPACT RIO device (NATIONAL INSTRUMENT).

The tests management, acquisition and data analysis are performed by software running on a conventional PC. This second software controls each test sequence: from the filling of the PWR fluid till the crack initiation estimation through sending orders to the CRIO software and the EUROTHERM controllers.

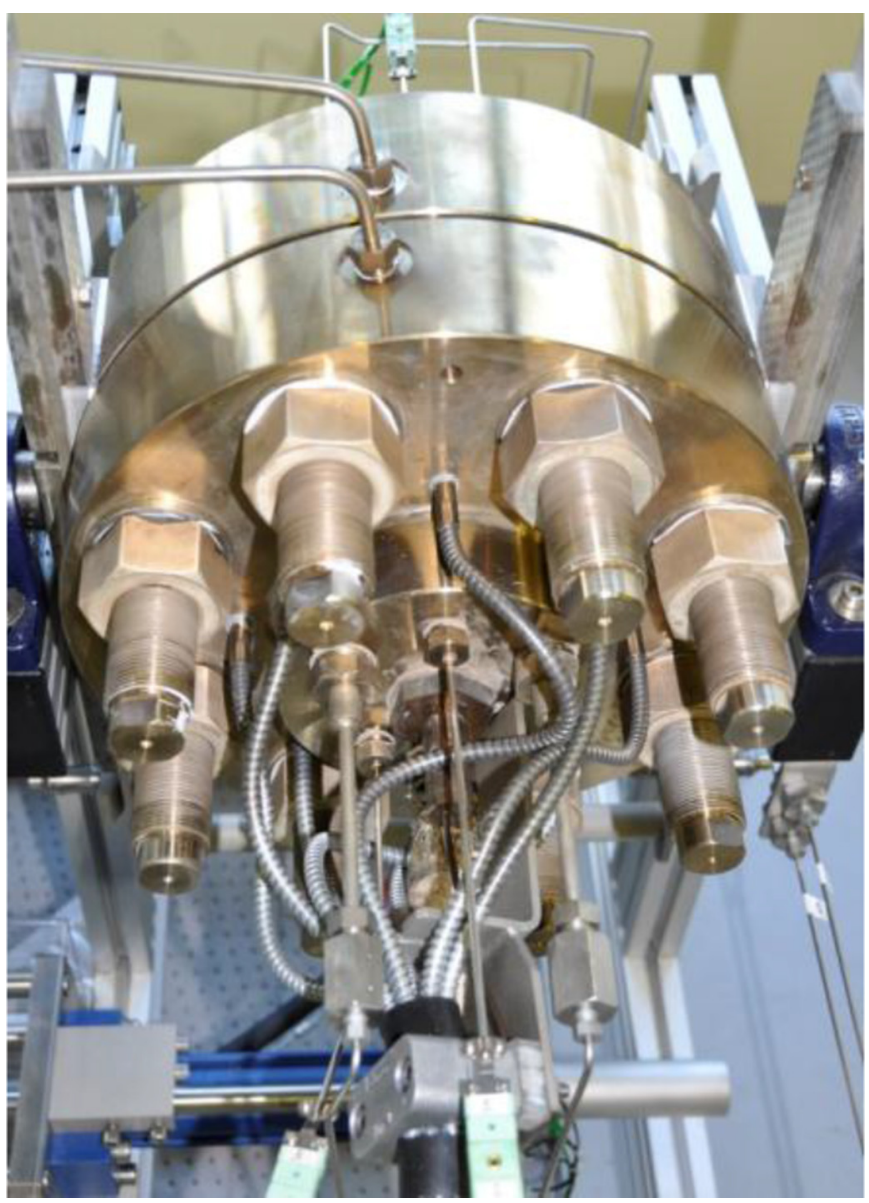

Fig. 12. Detail of the FABIME2E cell - attachment stud.

\section{Conclusion}

This paper focuses on the description of two kinds of experimental devices to perform fatigue tests on "structural" specimen with or without the effect of PWR environment.

The first device (FABIME2) is devoted to study the effect of biaxiality and mean strain/stress on the fatigue life. Biaxial fatigue tests are carried out on two austenitic stainless steels: 316L THY and 304L CLI. The results obtained show that crack initiation have a low impact on the fatigue life, which remains in the field covered by the design curve defined and used in the codification.

A second and new device based on FABIME2 is under development for the study of the impact of the environmental effect. This device will study the impact of the equibiaxial loadings with a primary water environment PWR $\left(300^{\circ} \mathrm{C}\right.$ with a permanent pressure of 140 bars $)$. The description of this device (FABIME2E) is the objective of this paper.

F. Datcharry and M. Rousseau from CEA are very greatly acknowledged for their participation in the FABIME2E conception. 


\section{References}

[1] NUREG/CR-6909, Rev. 0, Effect of LWR Coolant Environments on the Fatigue Life of Reactor Materials, 2007, O.K. Chopra and W.J. Shack

[2] RCC-M - Design and Construction Rules for mechanical components of nuclear PWR islands - 2007 edition with addenda in 2008, 2009 and 2010

[3] EN-13445-3 V1 standard, Unfired pressure vessels - Part 3: Design, December 2014

[4] RCC-MRx, Règles de Conception et de Construction des Matériels Mécaniques des Installations Nucléaires applicables aux structures à haute température et à l'enceinte à vide ITER, AFCEN Code, Association Française pour les Règles de Conception et de Construction des chaudières Électronucléaires. www.afcen.com, 2012

[5] A. Fissolo et al., Crack Initiation under thermal fatigue: an overview of CEA experience, Part 1: thermal fatigue appears to be more damaging than uniaxial isothermal fatigue, Int. J. Fatigue 31, 587-600 (2009)

[6] L. De Baglion, Comportement et endommagement en fatigue oligocyclique d'un acier inoxydable austénitique 304L en fonction de l'environnement (vide, air, eau primaire REP) à $300^{\circ} \mathrm{C}$, Thèse de l'Ecole Nationale Supérieure de Mécanique et d'Aérotechnique, 2006

[7] D.F. Lefebvre, Hydrostatic Pressure effect on Life Prediction in Biaxial Low-cycle fatigue, in: Biaxial and Multiaxial Fatigue: EGF 3, John Wiley \& Sons, Chichester, 1989
[8] T. Itoh et al., A design procedure for assessing low cycle fatigue life under proportional and non-proportional loading, Int. J. Fatigue 28, 459-466 (2006)

[9] M.W. Parsons, K.J. Et Pascoe, Development of a biaxial fatigue testing rig, J Strain Anal. 10, 1-3 (1975)

[10] H. Shimada, K. Shimizu, M. Obata, K. Chikugo, M. Chiba, A new biaxiaI testing machine for the flat specimen and a fundamental study on the shape of the specimen, Technol. Rep., Tohoku University 42, 1976, 351-369

[11] M. Poncelet et al., Biaxial high cycle fatigue of a type $304 \mathrm{~L}$ stainless steel: cyclic strains and crack initiation detection by digital image correlation, Eur. J. Mech. A/Solids 29, 810-825 (2010)

[12] S. Bradai et al., Crack initiation under equibiaxial fatigue, development of a particular equibiaxial fatigue device, PVP2013-97200, 2013

[13] S. Bradaï, C. Gourdin, C. Gardin, Study of crack propagation under fatigue equibiaxial loading, PVP2014-28417, ASME PVP 2014

[14] S. Bradaï, C. Gourdin et al., Equi-biaxial loading effect on austenitic stainless steel fatigue life, PVP2015-45293, ASME PVP 2015

[15] K.D. Ives, L.F. Kooistra, J.T. Tucker, Equibiaxial low-cycle fatigue properties of typical pressure-vessel steels, J. Basic Eng. Trans. ASME Ser. D 88, 745-754 (1966)

[16] J. Shewchuk, S.Y. Zamrik, J. Marin, Low-cycle fatigue of 7075-T651 aluminum alloy in biaxial bending, Exp. Mech. 8, 504-512 (1968)

[17] M. Kamaya, Development of disc bending fatigue test technique for equi-biaxial loading, Int. J. Fatigue 82, 561-571 (2016)

Cite this article as: C. Gourdin, G. Perez, H. Dhahri, S. Courtin, J.C. Le Roux, H. Maitournam, PWR effect on crack initiation under equi-biaxial loading development of the experiment, Mechanics \& Industry 20, 619 (2019) 